정규논문 (Regular Paper)

방송공학회논문지 제18권 제1호, 2013년 1월 (JBE Vol. 18, No. 1, January 2013)

http://dx.doi.org/10.5909/JBE.2013.18.1.31

ISSN 2287-9137 (Online) ISSN 1226-7953 (Print)

\author{
고품질의 3D 콘텐츠 제작을 위한 베이지안 접근방식의 사진측량기반 \\ 편위수정기법 개발 \\ 김 재 인 ${ }^{a}$, 김 태 정 ${ }^{a^{\ddagger}}$
}

\title{
Development of Photogrammetric Rectification Method Applying Bayesian Approach for High Quality 3D Contents Production
}

\author{
Jae-In $\mathrm{Kim}^{\mathrm{a})}$ and Taejung $\mathrm{Kim}^{\mathrm{a}}{ }^{\ddagger}$
}

요 약

본 논문에서는 고품질의 3D 콘텐츠 제작에 있어 입체피로를 최소화하기 위한 영상의 수직시차 교정방법으로, 베이지안 접근방식을 적용한 사진측량기반의 강인 편위수정 기법을 제안하고자 한다. 영상의 수직시차 제거 과정은 크게 기하추정 단계와 에피폴라 변환 단 계로 구성된다. 본 논문에서는 기하추정을 위해 사진측량에서 널리 활용되고 있는 공면조건 기반의 상대표정 알고리즘을 적용한다. 이 때 상대표정 알고리즘에는 자동 정합점 추출에 따른 오정합과 위치오차에 강인성을 확보하기 위해 제약조건을 도입한 베이지안 접근 방식을 적용하고자 하며, 이를 바탕으로 수행되는 에피폴라 변환에는 영상의 왜곡과 원 영상 대비 변형을 최소화하기 위한 공선조건기 반의 중심투영변환기법을 적용하고자 한다. 알고리즘의 성능검증을 위한 비교 알고리즘으로, 기하추정에는 일반적인 상대표정 알고리 즘과 컴퓨터비전분야의 8점 알고리즘 및 스테레오 캘리브레이션 기법이 사용되었으며, 에피폴라 변환에는 Hartley 방법과 Bouguet 방 법이 사용되었다. 실험결과는 제안 알고리즘의 높은 정확도와 여러 오차요인들에 대한 강인성, 그리고 최소화된 영상변형의 결과를 보 여주었다.

\begin{abstract}
This paper proposes a photogrammetric rectification method based on Bayesian approach as a method that eliminates vertical parallax between stereo images to minimize visual fatigue of $3 \mathrm{D}$ contents. The image rectification consists of two phases; geometry estimation and epipolar transformation. For geometry estimation, coplanarity-based relative orientation algorithm was used in this paper. To ensure robustness for mismatch and localization error occurred by automation of tie point extraction, Bayesian approach was applied by introducing several prior constraints. As epipolar transformation perspective transformation was used based on condition of collinearity to minimize distortion of result images and modification for input images. Other algorithms were compared to evaluate performance. For geometry estimation, traditional relative orientation algorithm, 8-points algorithm and stereo calibration algorithm were employed. For epipolar transformation, Hartley algorithm and Bouguet algorithm were employed. The evaluation results showed that the proposed algorithm produced results with high accuracy, robustness about error sources and minimum image modification.
\end{abstract}

Keyword : Stereovision, 3D Movie, Rectification, Epipolar geometry, Photogrammetry, Bayesian approach 


\section{I. 서 론}

$3 \mathrm{D}$ 콘텐츠 제작을 위한 실제 촬영현장에서는 입체피로 의 주원인이 되는 영상간의 수직시차 발생을 억제하기 위 해 카메라 리그(rig)라 불리는 고가의 특수촬영장비가 사용 된다. 이 장비는 카메라 배치형태에 따라 수직리그와 수평 리그로 나뉘며, 정밀한 카메라 조정이 가능하여 촬영 전 영 상간의 수직시차 제거를 위한 카메라 정렬작업에 널리 활 용되고 있다. 그러나 이와 같은 카메라 정렬작업은 사람에 의해 수동으로 진행되는 작업이기 때문에 완벽하게 수직시 차를 제거하는 것은 현실적으로 이루어지기 어렵다고 볼 수 있으며, 게다가 작업과정에 있어서도 전문적 기술과 경 험이 요구되기 때문에 원활한 $3 \mathrm{D}$ 콘텐츠 제작과 보급에 있 어 커다란 제약사항으로 작용하고 있는 실정이다. 이러한 이유로 콘텐츠 제작의 후반부 과정에서는 촬영단계에서 발 생된 영상간의 수직시차 문제를 해결하기 위해 추가적인 후처리 작업이 필수적으로 요구된다 ${ }^{[1,2]}$.

영상의 수직시차 불일치 문제는 편위수정(rectification) 이라 불리 우는 영상의 기하학적 변환기법을 통해 제거가 가능하다. 그 결과로 두 영상은 공간상에서 동일평면 위에 놓이게 되어, 영상간의 모든 정합점들은 동일한 수직좌표 를 가지게 된다. 일반적으로 $3 \mathrm{D}$ 콘텐츠 제작과정의 후반부 과정에서는 영상간의 수직시차를 제거하기 위한 방법으로 컴퓨터 비전방식의 편위수정 기법이 널리 활용되고 있다. 이들 기법은 카메라 보정정보(calibration data)의 유무에 따 라 크게 calibrated case와 uncalibrated case로 구분되고 있 다. 먼저, calibrated case는 각 카메라의 내부 및 외부인자 를 사전에 알고 있다는 가정 하에서 이루어진다. 여기서 카 메라 내부인자는 카메라 고유의 특성인자인 초점거리, 주 점의 위치 등을 의미하며, 반면 외부인자는 촬영시점과 촬

a) 인하대학교 지리정보공학과 (Dept. of Geoinformatic Engineering Inha University)

‡ Corresponding Author : 김태정 (Taejung Kim)

E-mail: tezid@inha.ac.kr

Tel: $+82-32-860-7608$

※본 연구는 인하대학교 교내연구비, 공간정보 전문인력 양성사업 및 2011년도 정부(교육과학기술부)의 재원으로 한국연구재단의 지원을 받 아 수행된 연구임(2011-0009721)

Manuscript received September 13, 2012 Revised November 1, 2012 Accepted December 12, 2012
영장소마다 변경될 수 있는 카메라의 자세각 및 위치 등을 의미한다. 보통 이러한 카메라 보정정보는 체스보드(chess board)와 같은 보정패턴을 촬영하여 획득된다 ${ }^{[3,4]}$. 하지만 이 작업은 본 촬영 전에 반드시 선행되어야한다는 점 때문 에 실제 활용에 있어서는 큰 제약사항으로 작용하게 된다. 이런 이유로 calibrated case에서 수행되는 편위수정 방식은 두 카메라가 일체형으로 제작되거나 또는 영구적으로 고정 된 형태일 때, 더 적합한 방법이라 할 수 있다.

반면 uncalibrated case는 사전에 카메라 보정정보가 획득 되기 어려운 경우에 수행되는 편위수정 방식을 의미한다. 이 때문에 실제 많은 컴퓨터비전 응용분야에서 이 방식이 널리 활용되고 있다 ${ }^{[5-9]}$. 일반적으로 uncalibrated case의 편 위수정 방식은 스테레오 영상의 에피폴라 기하(epipolar geometry)을 설명하는 기본행렬(fundamental matrix)을 기반 으로 이루어진다. 여기서 기본행렬은 스테레오 영상간의 기하학적 관계를 설명해주는 $3 \times 3$ 의 정방행렬로서, 영상에 서 획득된 정합점들의 위치정보만으로도 추정이 가능하다 는 장점이 있다. 하지만 이를 이용하여 수행되는 편위수정 방식은 카메라 보정정보를 통해 수행되는 calibrated case의 결과보다 상대적으로 낮은 정확도와 영상에 불필요한 왜곡 이 발생될 수 있다는 문제점이 있다.

이에 본 논문의 선행연구에서는 기존 방식의 문제점 을 보완하기 위한 방법으로, 사진측량기반의 상대표정 기법을 적용하여 영상간의 기하구조를 정밀하게 추정하 고 이로부터 중심투영변환을 수행함으로써 영상의 수직 시차 및 왜곡을 최소화하는데 좋은 결과를 성취하였다 ${ }^{[10]}$. 그러나 이러한 방식마저도 기존 방식과 마찬가지로 오직 영상의 정합점만을 이용하여 기하구조를 추정해야 하기 때문에 정합점의 위치오차에 민감할 뿐 아니라, $3 \mathrm{D}$ 영화와 같은 연속된 영상 시퀀스로 이루어진 콘텐츠의 경우에는 실제 대상장면에 대한 모델공간 좌표계를 기 준으로, 장면을 구성하는 프레임들이 서로 동일한 기하 구조로 추정되기 어렵다는 문제점이 발생하였다. 이로 인해 영상 시퀀스의 편위수정 결과는 각각의 프레임들 이 서로의 연속성을 잃게 되어 결과적으로, 대상 장면에 대한 흔들림 현상을 유발하게 되었고, 이러한 현상은 오 차요인의 증가에 따라 더욱 크게 나타났다. 이는 특정 
장면을 대표할 기하구조의 결정을 어렵게 만들뿐 아니 라 잘못된 결과를 선택함에 따라 $3 \mathrm{D}$ 콘텐츠의 전반적인 품질을 저하시키게 되는 주된 요인으로 작용되기 쉽다.

카메라 정렬 오류로 인해 발생된 영상간의 수직시차 교 정 작업은 $3 \mathrm{D}$ 영화의 경우, 입체피로를 최소화하기 위해 필수적으로 요구되는 과정이며, 또한 최근 활발히 연구되 고 있는 실감방송 서비스의 경우에도 다시점 영상의 정렬 과 깊이영상 제작을 위한 효율적 방안으로서 매우 중요한 역할을 담당하고 있다. 이에 본 논문에서는 기존 방식의 문 제점으로 언급한 기하추정의 강인성 및 안정성 문제를 해 결하기 위해 베이지안 접근방식을 적용한 사진측량기반의 강인 편위수정 기법을 제안하고자 한다.

\section{II. 제안 알고리즘}

기존 사진측량기반의 영상 편위수정 기법은 크게 기하추 정 단계와 에피폴라 변환단계로 나눌 수 있다 ${ }^{[12]}$. 먼저, 첫 번째 기하추정 단계에서는 모델공간상에 두 영상간의 상대 적인 자세와 위치를 추정하여 기하학적 관계를 복원하기 위한 상대표정 작업이 수행된다. 일반적으로 이러한 기하 관계를 설명하는 수학적 모델은 비선형 방정식의 형태를 가지기 때문에, 상대표정 과정에는 테일러 전개를 통한 모 델 방정식의 선형화와 최소제곱조정을 통한 반복적 추정과 정이 포함된다. 다음의 에피폴라 변환단계에서는 앞 서 추 정된 영상간의 상대표정요소(상대적 자세와 위치요소)로부 터 에피폴라 변환이 이루어지게 된다. 이 과정을 통해 두 영상 간에 발생된 수직시차는 정확하게 제거될 수 있다. 그 러나 이 과정은 표정요소의 추정 정확도에 민감하게 반응 하기 때문에 상대표정 과정에서 정확하고 강인한 추정이 보장될 필요가 있다. 다음의 세부 절에서는 고품질의 $3 \mathrm{D}$ 콘텐츠 제작을 위해 본 논문에서 제안하고자 하는 상대표 정방법과 에피폴라 변환방법에 대해 각각 상세히 기술한다.

\section{1. 베이지안 접근방식을 적용한 상대표정}

에피폴라 기하학은 두 영상간의 기하학적 관계를 설명할
때 대표적으로 사용되고 있는 개념으로, 에피폴라 기하 수 립을 위한 제약조건식(또는 공면조건식)은 그림 1에 묘사 된 공간상의 벡터들로부터 식 (1)과 같이 표현할 수 있다. 여기서 $T, P_{1}, P_{2}$ 는 각각 $T=\overrightarrow{O_{1} O_{2}}, P_{1}=\overrightarrow{O_{1} P}, P_{2}=\overrightarrow{O_{2} P}$ 을 의미한다.

$$
\left(P_{1}-T\right)^{T} \cdot\left[T \times P_{1}\right]=0
$$

그리고 위 식은 벡터 $T=[T x, T y, T z]^{T}$ 라 했을 때, 다음 의 식 (2)과 같이 행렬 간 곱의 형태로 정리할 수 있다.

$$
\begin{aligned}
\left(P_{1}-T\right)^{T} \cdot\left[T \times P_{1}\right] & =P_{2}^{T} S P_{1} \\
& =P_{2}^{T}\left[\begin{array}{ccc}
0 & -T z & T y \\
T z & 0 & -T x \\
-T y & T x & 0
\end{array}\right] P_{1}=0
\end{aligned}
$$

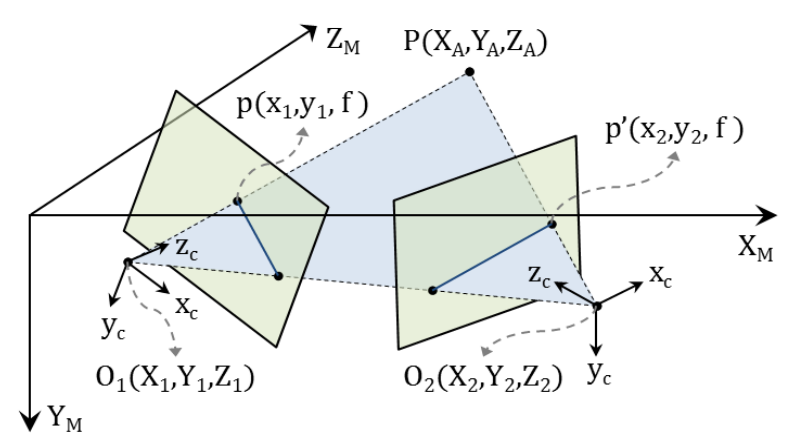

그림 1. 모델 공간과 카메라 공간에서의 에피폴라 기하

Fig. 1. Epipolar geometry in model and camera space

일반적으로 사진측량분야에서는 종속적 상대표정을 위 해 좌측 영상의 카메라 공간좌표계를 모델 공간좌표계와 동일하게 배치하여, 우측영상의 자세각 요소와 위치요소만 을 실제 추정하고자 하는 모델 방정식의 미지수로 간주하 게 된다. 이 때, 우측영상의 위치요소 중 $\mathrm{X}$ 방향의 투영중심 위치는 모델 공간의 스케일과 관련된 요소이기 때문에 적 당한 상수로 고정하게 되면, 결과적으로 모델 방정식의 실 질적인 미지수 개수는 총 5 개로 최소화할 수 있게 된다. 이 는 실제 촬영 환경상의 구조적 특성에 따라 유연한 조정이 가능하다. 5 개 표정요소를 미지수로 하는 종속적 상대표정 을 위해 식 (2)의 공면조건식을 모델 방정식으로 하여, 카메 
라 공간좌표계로 나타내면 카메라 공간상의 벡터 $p_{1}, p_{2}$ 와 모델 좌표계에 대한 우측영상의 회전행렬 $R_{2}$ 로부터 다음 의 식 (3)과 같이 표현할 수 있게 되며,

$$
\begin{aligned}
& F\left(\omega, \phi, \kappa, T_{Y}, T_{Z}\right) \\
= & p_{2}^{T} R_{2} S p_{1} \\
= & {\left[\begin{array}{ll}
x_{2} & y_{2} f
\end{array}\right]\left[\begin{array}{l}
r_{11} r_{12} r_{13} \\
r_{21} r_{22} r_{23} \\
r_{31} r_{32} r_{33}
\end{array}\right]\left[\begin{array}{ccc}
0 & -T_{Z} & T_{Y} \\
T_{Z} & 0 & -T_{X} \\
-T_{Y} & T_{X} & 0
\end{array}\right]\left[\begin{array}{c}
x_{1} \\
y_{1} \\
f
\end{array}\right] } \\
= & 0
\end{aligned}
$$

최소제곱조정을 통해 5 개의 표정요소를 구하기 위해서는 식 (4)와 같이 테일러 전개를 통한 선형화 과정이 요구된다.

$$
F\left(\omega, \phi, \kappa, T_{Y}, T_{Z}\right)=F_{i_{0}}+d F_{i}+\varepsilon=0
$$

여기서,

$$
\begin{gathered}
F_{i_{0}}=F\left(\omega^{0}, \phi^{0}, \kappa^{0}, T_{Y}^{0}, T_{Z}^{0}\right)=-w_{i} \\
d F_{i}=\left[\frac{\partial F_{i}}{\partial \omega} \frac{\partial F_{i}}{\partial \phi} \frac{\partial F_{i}}{\partial \kappa} \frac{\partial F_{i}}{\partial T_{Y}} \frac{\partial F_{i}}{\partial T_{Z}}\right] d x=A_{i} d x \\
d x=\left[\Delta \omega \Delta \phi \Delta \kappa \Delta T_{Y} \Delta T_{Z}\right]^{T}
\end{gathered}
$$

위 수식 (4)와 같이 모델 방정식이 선형화되고 나면, 다음 식 (8)와 같은 형태로 식을 구성하여 반복적인 최소제곱조 정을 통해 최종 표정요소들을 정확하게 결정할 수 있게 된 다. 이 과정에서 미지수로 간주되는 5 개 표정인자의 초기값 은 모두 ' 0 '으로 설정된다. 이는 일반적인 스테레오 촬영에 있어 두 카메라가 가지는 구조적 배치에 기인한다.

$$
A d x+\varepsilon=w, d x=\left(A^{T} A\right)^{-1} A^{T} w
$$

그러나 이러한 상대표정방식 역시도 앞 서 서론에서 언 급한 바와 같이 기본행렬 기반의 편위수정 방식에서 나타 나는 기하구조 추정상의 비일관성 문제가 동일하게 발생될 수밖에 없다. 이는 두 영상 간 정합지점에 해당하는 모델 공간상의 대응점이 부재하여, 절대표정이 이루어질 수 없 다는 점에 원인을 두고 있다. 이에 본 논문에서는 상기의
일반적인 상대표정방식이 아닌, 사전정보의 도입을 통해 표정요소의 추정 안정도를 향상시키기 위한 방안으로 베이 지안 접근방식을 기반으로 하는 상대표정 기법을 적용하고 자 한다.

베이지안 접근방식을 따르는 최소제곱조정과정에서 사 전 제약조건은 가중치의 형태로 도입된다. 이를 위해 수식 (8)은 다음의 수식 (9)와 같이 가중최소제곱조정의 형태로 변형될 수 있으며, 이 과정에서 방정식 행렬 $A$ 는 미지수 보정인자에 대한 사전 제약조건들까지 고려하기 위해 수식 (10)에서와 같이 행렬 $B$ 의 형태로 변형된다 ${ }^{[1]}$. 이러한 부 분이 일반적인 가중최소제곱조정법과 다른 점이라 할 수 있으며, 이로 인해 각각의 관측방정식에 대한 제약조건뿐 만 아니라 미지수 보정인자에 대한 제약조건까지도 미지수 추정과정에 기여할 수 있게 된다.

$$
B d x+\varepsilon=w, d x=\left(B^{T} C_{w}^{-1} B\right)^{-1} B^{T} C_{w}^{-1} w
$$

여기서,

$$
B=\left[\begin{array}{c}
A \\
I
\end{array}\right], w=\left[\begin{array}{l}
w_{p} \\
w_{x}
\end{array}\right], C_{w}=\left[\begin{array}{cc}
C_{p} & 0 \\
0 & C_{x}
\end{array}\right]
$$

$w_{p}$ : 입력 정합점에 대한 카메라 공간좌표의 폐합오차(misclosures) 벡터 $w_{x}:$ 미지수 보정인자들에 대한 폐합오차 벡터

$C_{p}:$ 카메라 공간좌표계상에서 정합점 위치좌표에 대한 사전 공분산 행렬 $C_{x}:$ 미지수 보정인지들의 사전 공분산 행렬

결과적으로 이러한 접근방식은 최소제곱조정과정에서 각 미지수 보정인자들이 가질 수 있는 값의 변동폭을 사 전에 주어진 제약조건에 따라 각각 다르게 제한함으로 써 주어진 제약조건을 최대한 만족시키며 정확도 높은 미지수 추정을 가능하게 한다. 따라서 미지수 보정인자 들에 대한 사전 제약조건을 실제 카메라 배치의 구조적 특성을 근거로 부여하게 된다면, 앞 서 문제점으로 제 기된 기하구조 추정상의 비일관성 문제와 오차요인에 대한 민감성 문제 모두를 해소하는데 큰 역할을 하게 될 것이다. 실제 알고리즘에 적용될 사전 제약조건의 결정은 추후 3 장에서 상세하게 다루어진다. 


\section{2. 공선조건을 이용한 에피폴라 변환}

에피폴라 변환은 수립된 기하구조를 바탕으로 스테레오 영상간의 수직시차를 제거함으로써 입체시가 가능한 상태 로 만드는 영상의 기하학적 변환을 의미한다. 사진측량분 야에서는 이러한 목적을 달성하기 위해, 일반적으로 공선 조건식을 이용한 중심투영변환 기법이 널리 사용되고 있다.

공선조건식을 이용한 중심투영변환 기법은 모델 공간좌 표계에 대한 수직영상변환과 촬영기선에 대한 수직영상변 환으로 구성된다 ${ }^{[12]}$. 여기서 모델 공간좌표계에 대한 수직 영상변환은 모델 공간에 대해 회전요소가 모두 ' 0 '인 수직 상태인 영상으로의 변환을 의미한다. 앞 절에서 설명한바 와 같이, 본 논문에서는 두 영상간의 상대표정요소를 추정 하기 위해 종속적 상대표정방법을 적용하였기 때문에, 이 과정은 우측영상에 한해서만 이루어지게 된다(그림 2(a)). 그러나 그림 2(b)에서 설명하는바와 같이 기선에 대한 수직 영상변환은 모델 공간좌표계에 대해 두 영상 모두 기선에 대한 회전요소를 가지게 되기 때문에, 양측 영상 모두에 적 용될 필요가 있다.

촬영기선에 대한 각각의 회전요소 $\Omega, \Phi, K$ 는 우측영상 의 위치요소 $T x, T y, T z$ 로부터 다음 수식 (11)과 같이 계 산할 수 있다.

$$
\Omega=\frac{\omega_{1}+\omega_{2}}{2}, \Phi=-\tan ^{-1} \frac{T_{Z}}{\left(T_{X}^{2}+T_{Y}^{2}\right)^{1 / 2}}, K=\tan ^{-1} \frac{T_{Y}}{T_{X}}
$$

그리고 두 영상간의 수직시차를 제거하기 위한 회전행렬 $R_{T}$ 는 모델공간에 대한 회전변환행렬 $R^{T}$ 와 촬영기선에 대 한 회전변환행렬 $R_{B}$ 로부터 수식 (12)와 같이 정의된다.

$$
R_{T}=R_{B} R^{T}, R_{B}=R_{\Omega} R_{\Phi} R_{K}
$$

이 후 회전행렬 $R_{T}$ 는 공선조건식에 대입되어 수직시차 제거를 위한 에피폴라 영상제작에 사용된다. 다음 수식 (13) 은 원 영상 위의 한 점 $\left(x_{o}, y_{o}\right)$ 이 공선조건에 의해 수직영상 위의 한 점 $\left(x_{r}, y_{r}\right)$ 으로 투영되는 과정을 보여준다. 이 때, 식의 $r_{11}, \cdots, r_{33}$ 은 회전행렬 $R_{T}$ 의 행렬요소를 의미한다.

$$
\begin{aligned}
& x_{r}=f_{r} \times \frac{r_{11} x_{o}+r_{12} y_{o}+r_{13} f_{o}}{r_{31} x_{o}+r_{32} y_{o}+r_{33} f_{o}} \\
& y_{r}=f_{r} \times \frac{r_{21} x_{o}+r_{22} y_{o}+r_{23} f_{o}}{r_{31} x_{o}+r_{32} y_{o}+r_{33} f_{o}}
\end{aligned}
$$

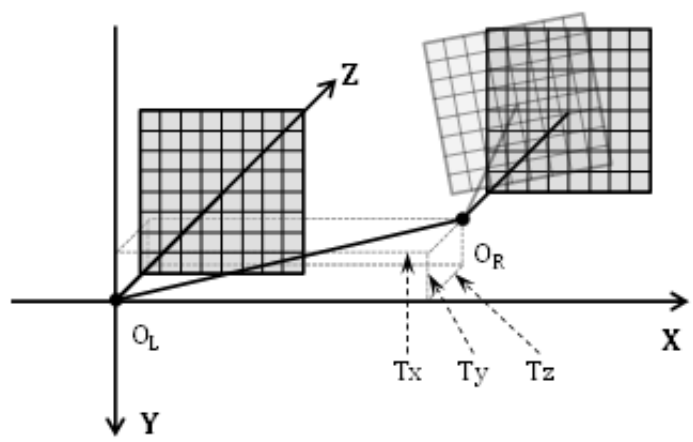

(a) 모델공간에 대한 수직영상변환

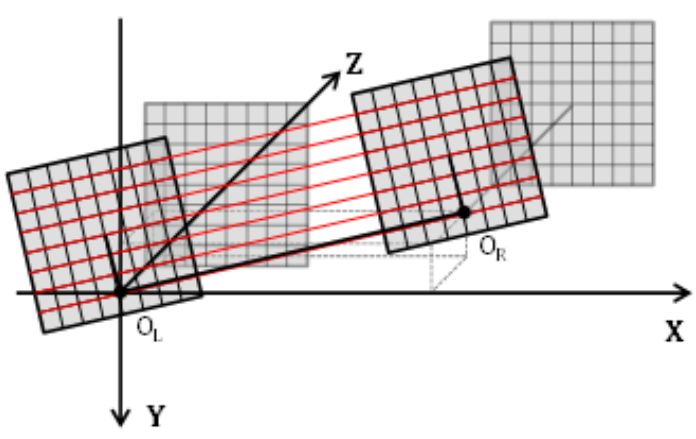

(b) 촬영기선에 대한 수직영상변환

그림 2. 종속적 상대표정에 따른 에피폴라 변환과정

Fig. 2. Epipolar resampling via dependant relative orientation

\section{III. 실험 결과 및 분석}

\section{1. 실험환경 및 방법}

제안 알고리즘의 성능분석을 위해 웹캠 두 대를 이용하 여 실험데이터를 취득하였다. 실험데이터는 카메라 자세 및 위치를 고정한 채 피사체의 움직임만이 존재하도록 하 여, 연속적인 100 장의 시퀀스 형태로 2 개 세트(TEST 01, TEST 02)가 제작되었다. 이 때, 촬영과정에서 TEST 01의 


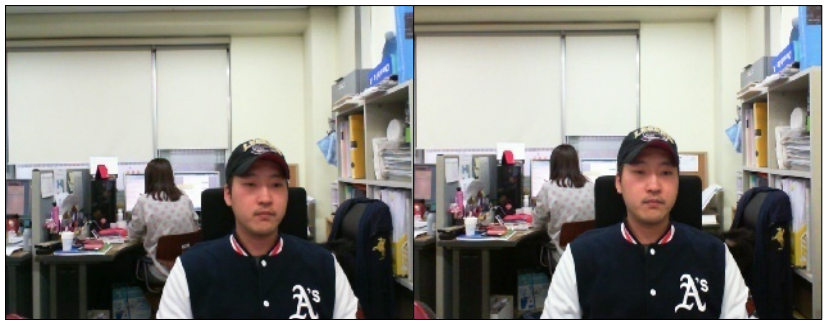

(a) TEST 01

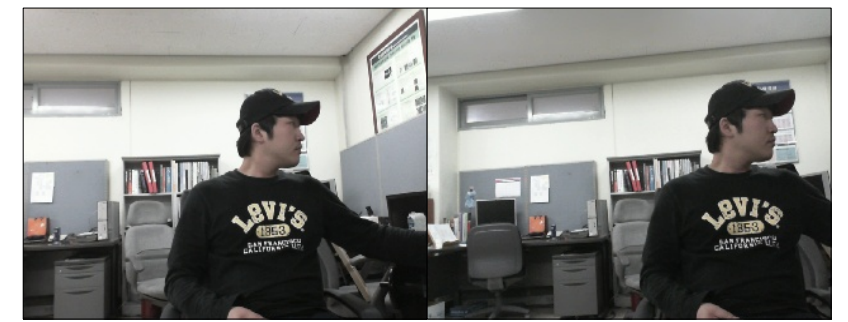

(b) TEST 02

그림 3. 검증실험을 위해 제작된 영상 데이터셋 (영상크기: $320 \times 240$, 카메라: Microsoft LifeCam Cinema)

Fig. 3. Image datasets made for performance evaluation (Image size: 320×240, Camera: Microsoft LifeCam Cinema)

경우는 대략적인 카메라 조정을 통해 자세 차이가 크게 나 지 않게 하였으며, 반대로 TEST 02 는 카메라 간 자세 차이 에 따른 영향을 분석하고자 다소 차이를 두어 제작하였다. 다음의 그림 3은 실험에 사용된 영상 데이터셋을 보여준다.

알고리즘의 성능분석에 있어, 에피폴라 기하 추정에는 비 교 알고리즘으로 8점 알고리즘을 사용하였으며, 추가적으 로 패턴영상을 이용한 스테레오 조정 알고리즘과 기존 상대 표정 알고리즘 ${ }^{[10]}$ 또한 구현하여 성능을 분석해보았다. 에피 폴라 변환 알고리즘으로는 기본행렬 방식에 적합한 Hartley 알고리즘 ${ }^{[13]}$ 이 비교 알고리즘으로 사용되었으며, 스테레오 조정방식에는 Bouguet 알고리즘 ${ }^{[14]}$ 이 사용되었다. 다음의 표 1은 케이스별 알고리즘의 조합형태를 정리한 것이다.

표 1. 성능비교 검증을 위한 방식별 비교 알고리즘의 조합형태

Table 1. Cases of comparison algorithms for performance evaluation

\begin{tabular}{c|c|c}
\hline \hline 방식 & 기하추정 & 에피폴라 변환 \\
\hline Case 1 & 8점 알고리즘 & Hartley 변환 알고리즘 \\
\hline Case 2 & $\begin{array}{c}\text { 정규화된 } \\
\text { 8점 알고리즘 }\end{array}$ & Hartley 변환 알고리즘 \\
\hline Case 3 & $\begin{array}{c}\text { 스테레오 캘리브레이션 } \\
\text { 알고리즘 }\end{array}$ & Bouguet 변환 알고리즘 \\
\hline Case 4 & 상대표정알고리즘 & 중심투영변환 알고리즘 \\
\hline $\begin{array}{c}\text { Case 5 } \\
\text { (제안방식) }\end{array}$ & $\begin{array}{c}\text { 베이지안 } \\
\text { 상대표정 알고리즘 }\end{array}$ & 중심투영변환 알고리즘 \\
\hline \hline
\end{tabular}

에피폴라 기하추정을 위한 정합점 추출에는 SIFT(Scale Invariant Feature Transform) ${ }^{[15]}$ 알고리즘이 사용되었으 며, 특히 TEST 02의 경우는 제안 알고리즘의 강인성 분
석을 목적으로 오정합점 제거를 위한 RANSAC(RANdom SAmple Consensus) ${ }^{[16]}$ 적용 시 허용오차를 TEST 01에 비 해(TEST 01의 허용오차는 1 pixel로 설정) 3 배 크게 설정하 여 정합점들을 추출하였다. 그리고 기하추정을 위한 모델 정합점과는 별개로 알고리즘의 성능분석을 위한 검사점은 직접 정밀하게 각 영상 데이터별로 10 점씩 추출하였다.

알고리즘의 성능을 정략적으로 분석하기 위해 사전에 취 득한 검사점들을 대상으로, 에피폴라 라인 추정정확도 $\left(e_{\text {line }}\right)$ 및 기울기의 변동폭 $\left(v_{\text {slope }}\right)$ 그리고 에피폴라 변환에 따른 수직시차 제거 정확도 $\left(e_{r e c t}\right)$ 등이 성능지표로서 측정 되었다. 여기서 에피폴라 라인 추정정확도는 검사점과 추 정된 에피폴라 라인과의 이격거리 오차를 의미하며, 변환 결과에 따른 수직시차 제거 정확도는 검사점들이 에피폴라 변환식에 따라 재투영되었을 때 정합점간에 발생되는 $\mathrm{Y}$ 좌 표 값의 차이를 의미한다. 마지막으로 에피폴라 라인 기울 기의 변동폭은 각각의 검사점에서 추정되는 에피폴라 라인 기울기의 표준편차를 의미하며, 이 성능지표를 통해 기하 수립의 일관성 정도를 측정하였다.

\section{2. 강인추정을 위한 제약조건의 결정}

본 논문에서 제안하는 상대표정 알고리즘은 일반적인 상 대표정 알고리즘과는 달리 각 모델점들로부터 수립된 관측 방정식들과 미지수 보정인자들에 대한 사전 제약조건(혹은 불확실성)으로부터 각각의 가중치를 계산하여 최소제곱조 정이 이루어지는 방식이라 할 수 있다. 여기서 각 관측방정 식에 대한 사전 제약조건은 스테레오 영상 간 정합점 측정 
상의 불확실성으로 정의될 수 있으며, 미지수 보정인자에 대한 사전 제약조건은 해당 미지수인자 초기값 설정에 따 른 불확실성으로 정의될 수 있다. 하지만 이와 같은 접근방 식을 적용한 기존 연구 ${ }^{[1]}$ 에서는 적용대상이 위성영상이라 는 특성 때문에 사전 제약조건들이 쉽게 정의 될 수 있었으 나, 본 논문의 경우는 촬영 환경적 특성상 그런 명확한 사전 정보의 도입이 용이치 못하다고 볼 수 있다. 따라서 본 논문 의 경우에는 실험을 통해 산출된 실제적인 값으로부터 사 전 제약조건이 결정될 필요가 있다.

제안 알고리즘에는 결정되어야 할 사전 제약조건이 총 $\mathrm{n}+5$ 개로, 이 중 $\mathrm{n}$ 개는 모델 정합점으로부터 수립된 관측방 정식 각각에 해당하는 제약조건이라 할 수 있으며, 5 개는 상대표정요소인 자세인자 3 개와 위치인자 2 개에 해당하는 보정인자들의 제약조건이라 할 수 있다. 이 때, 모델 정합점 들은 모두가 동일한 정확도로 측정되었기 때문에 각 관측 방정식에 해당하는 제약조건들은 하나의 값으로 간주해도 무방하다 볼 수 있다. 그리고 자세별, 위치별 보정인자들 끼리는 서로 동일한 제약조건을 갖게 될 것이기 때문에, 결 과적으로 사전에 결정되어야 할 제약조건은 총 3 개로 요약 될 수 있다.

제안 알고리즘에 요구되는 제약조건들을 보다 용이하게 도출하고자 본 논문에서는, 카메라들 간의 상대적 위치는 $\mathrm{X}$ 축 방향(카메라 리그 축의 방향)의 변위가 다른 $\mathrm{Y}, \mathrm{Z}$ 축 방향의 변위에 비해 지배적으로 클 것이라는 기하학적 가
정을 도입하였다. 이는 $3 \mathrm{D}$ 콘텐츠 촬영을 위한 카메라 배치 구조상의 특징을 근거로 적용되었으며, 이에 따라 최소제 곱조정과정에서 위치인자의 초기값 $(T y, T z)$ 으로 부여되는 ' 0 '의 값은 매우 정확한 값이라 간주할 수 있게 된 반면에 자세인자의 초기값으로 부여되는 ' 0 '의 값은 위치인자의 경우보다 상대적으로 더 큰 불확실성을 갖게 된다고 간주 할 수 있게 된다. 이로부터 자세 보정인자와 위치 보정인자 에 대한 제약조건의 차이를 임의로 크게 설정하고, 오직 관 측방정식에 대한 제약조건만을 독립변수 다루게 된다면, 제약조건들은 실험을 통해 쉽게 결정될 수 있다.

앞서 설명한 바와 같이 3 개 제약조건에 대한 적합한 값을 결정하기 위해, 일반적인 상대표정기법을 이용하여 TEST 01 각 프레임별 에피폴라 라인의 추정오차를 측정해 보았 다. 그런 다음에는 실험상의 효율을 목적으로 좋은 정확도 를 나타낸 몇 개의 프레임과 다소 큰 오차를 나타낸 몇 개의 프레임들만을 대상으로, 자세 보정인자 및 위치 보정인자 에 대한 제약조건은 고정한 채 관측방정식에 대한 제약조 건만을 조절해 가며 각 영상들의 정확도 변화를 살펴보았 다. 이 때, 실제 최소제곱조정에 적용되는 제약조건은 가중 치의 형태로 도입되기 때문에 각 제약조건에 해당하는 가 중치는 해당 제약조건 값의 역수로 계산되며, 본 실험에서 는 자세 보정인자 및 위치 보정인자에 대한 가중치를 각각 1 과 $1,000,000$ 으로 설정하고, 관측방정식에 대한 가중치는 초기 5.0 으로부터 400 회 반복 시행하는 동안 0.95 의 값을

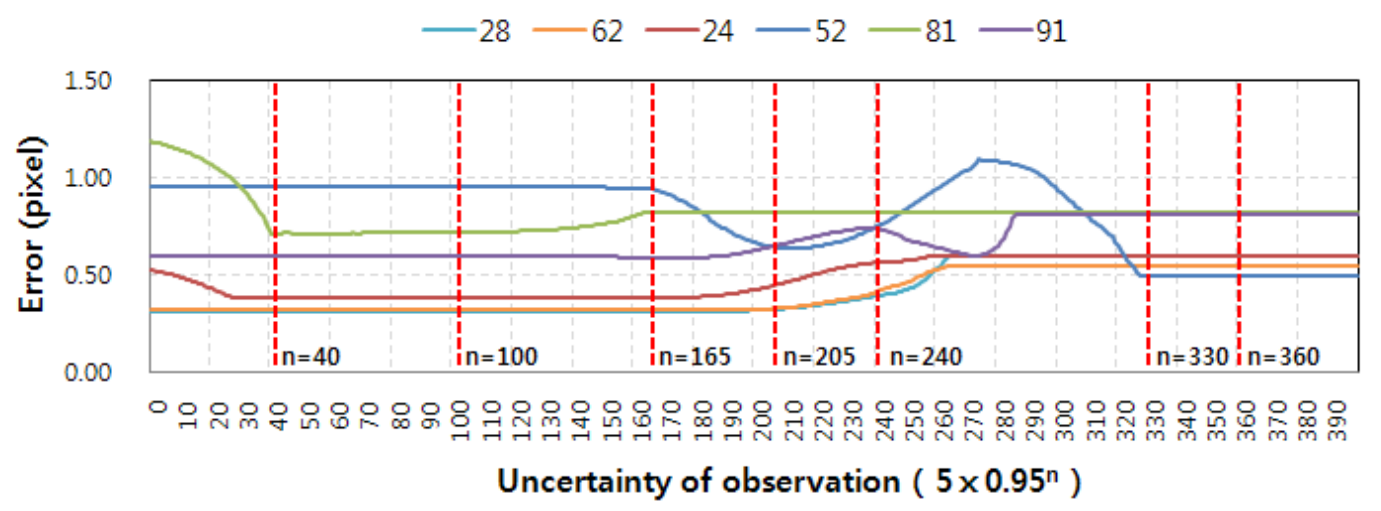

그림 4. 관측방정식에 대한 제약조건 조정에 따른 샘플영상 $(24,28,52,62,81,91$ 번째 프레임)의 에피폴라 라인 추정오차

Fig. 4. Epipolar line error of sample image frames according to decreasing weight of observation equations 
거듭 곱함에 따라 점차적으로 값의 크기를 감소시켜 나갔 다. 이는 결과적으로 모델방정식 내에서 관측방정식에 대 한 영향력은 감소됨에 따라, 반대로 미지수 보정인자들에 대한 제약조건의 영향력은 증가하게 되는 효과로 나타나게 되며, 미지수 보정인자 중 상대적으로 큰 가중치가 부여된 위치 보정인자의 변동 가능 폭은 줄어들고 반대로 자세 보 정인자의 변동 가능 폭은 증가하는 결과가 나타나게 된다. 다음의 그림 4는 샘플로 선정된 6 개 영상들에 대해 상기의 제약조건을 적용함에 따라 변화되는 에피폴라 라인 추정오 차를 나타낸 것이다.

실험결과에서 볼 수 있듯이 관측방정식에 부여된 가중치 가 점차적으로 감소됨에 따라 각 영상들의 오차는 증가 또 는 감소되는 모습을 보이다가, 약 $n=330$ 지점 이후부터는 수렴하는 형태를 나타내었다. 이에 본 논문에서는 그림 4 에 표시한 바와 같이 영상들의 정확도가 변하게 되는 몇몇의 관심지점들을 대상으로 TEST 01 전체 프레임에 대한 정확 도를 측정해보았다.

표 2는 관측방정식에 대한 가중치 변화에 따라 산출되는 성능측정결과와 표정요소들을 정리한 것이다. 결과에서 볼 수 있듯이 가중치가 감소됨에 따라 오차가 다소 증가되는 양상이 확인되었다. 그러나 $\mathrm{n}$ 이 330 인 지점에 이르렀을 때 는 오차의 표준편차가 이전 단계들과 비교해 보았을 때 상 대적으로 크게 감소하였으며, 이는 추정된 에피폴라 라인 기울기의 변동폭에서도 명확히 확인할 수 있었다. 또한 표 2 의 표정요소 추정결과를 보면, 우리가 처음 가정했던 것과 같이 $n$ 이 330 인 지점부터는 $T y$ 와 $T z$ 의 요소가 0 에 가까운 값으로 추정되었으며, 그 추정값의 표준편차 역시도 크게
감소된 결과를 볼 수 있었다. 이에 $n$ 이 330 일 때의 제약조건 하에서는 약간의 정확도 저감이 발생될지는 모르나 서브픽 셀의 정확도를 확보할 수 있고, 또한 오차에 대한 강인성 역시도 보장할 수 있다고 판단된다. 따라서 본 논문에서는 제안 알고리즘에 요구되는 제약조건을 결정함에 있어, 관측 방정식에 대한 제약조건을 $\mathrm{n}$ 이 330 인 경우로 채택하였다.

\section{3. 알고리즘 성능검증 결과 및 분석}

제안 알고리즘의 성능검증은 TEST 01과 TEST 02에 대 한 비교 알고리즘과의 성능비교를 통해 이루어졌다. 다음 의 표 3 은 각 알고리즘별 산출된 성능검증의 결과를 정리한 것이다.

먼저 TEST 01에 대한 알고리즘별 성능분석 결과를 보면, Case 1을 제외한 나머지 알고리즘 결과에서 대체적으로 유 사한 성능이 나타났음을 확인할 수 있었다. 이는 에피폴라 변환 정확도 측면에서 더욱 두드러지게 나타났다. 그러나 자세각 차이 및 정합점 위치오차 등의 문제요인들이 상대 적으로 더 많이 포함된 TEST 02의 결과에서는 이전 결과 와는 달리, 제안 알고리즘을 제외한 나머지 비교 알고리즘 들에서 약 0.2 픽셀 이상의 성능저하가 발생된 것을 확인할 수 있었다. 이러한 결과는 오차요인에 대한 제안 알고리즘 의 높은 강인성을 잘 보여준다고 할 수 있다.

또한 에피폴라 라인의 기울기 변동폭을 보면, 제안 알고 리즘의 경우 그 값이 매우 낮게 산출된 반면, 다른 비교 알 고리즘들의 경우에서는 모두 큰 변동이 나타났음을 확인할 수 있었다. 이는 논문의 서론에서도 잠시 언급했던 것과 같 이 기존 uncalibrated case의 편위수정 알고리즘들이 영상

표 2. 관측방정식에 대한 기중치 변화에 따른 TEST 01의 성능분석결과

Table 2. Experiment result of TEST 01 according to changing weight for observation equations

\begin{tabular}{c|c|c|c|c|c|c|c}
\hline \hline & $\begin{array}{c}e_{\text {line }} \\
\text { (pixel) }\end{array}$ & $\begin{array}{c}v_{\text {slope }} \\
(\mathrm{deg})\end{array}$ & $\begin{array}{c}\omega \\
(\mathrm{deg})\end{array}$ & $\begin{array}{c}\phi \\
(\mathrm{deg})\end{array}$ & $\begin{array}{c}\kappa \\
(\mathrm{deg})\end{array}$ & Ty & $T z$ \\
\hline $\mathrm{n}=40$ & $0.38 \pm 0.12$ & 3.08 & $-1.91 \pm 0.09$ & $-0.58 \pm 0.46$ & $-0.68 \pm 0.06$ & $2.49 \pm 4.10$ & $31.03 \pm 14.07$ \\
\hline $\mathrm{n}=100$ & $0.38 \pm 0.12$ & 3.08 & $-1.91 \pm 0.09$ & $-0.58 \pm 0.46$ & $-0.68 \pm 0.06$ & $2.49 \pm 4.10$ & $31.03 \pm 14.07$ \\
\hline $\mathrm{n}=165$ & $0.38 \pm 0.12$ & 2.99 & $-1.91 \pm 0.09$ & $-0.59 \pm 0.45$ & $-0.68 \pm 0.06$ & $2.42 \pm 4.05$ & $30.50 \pm 13.45$ \\
\hline $\mathrm{n}=205$ & $0.40 \pm 0.11$ & 2.37 & $-1.92 \pm 0.10$ & $-0.89 \pm 0.35$ & $-0.65 \pm 0.06$ & $0.40 \pm 4.09$ & $20.41 \pm 7.85$ \\
\hline $\mathrm{n}=240$ & $0.45 \pm 0.10$ & 2.19 & $-1.96 \pm 0.11$ & $-1.29 \pm 0.35$ & $-0.59 \pm 0.06$ & $-2.76 \pm 4.30$ & $8.18 \pm 3.54$ \\
\hline $\mathrm{n}=330$ & $0.57 \pm 0.07$ & 0.29 & $-1.87 \pm 0.03$ & $-1.67 \pm 0.44$ & $-0.59 \pm 0.04$ & $-0.16 \pm 0.55$ & $0.16 \pm 0.11$ \\
\hline $\mathrm{n}=360$ & $0.58 \pm 0.08$ & 0.10 & $-1.87 \pm 0.03$ & $-1.68 \pm 0.46$ & $-0.59 \pm 0.04$ & $-0.02 \pm 0.13$ & $0.02 \pm 0.03$ \\
\hline \hline
\end{tabular}


시퀀스 처리에 대한 별도의 고려 없이 오직 영상간의 정합 점만을 이용하여 상대적 기하구조를 추정하기 때문에 나타 난 결과라 할 수 있다. 즉, 이는 기존 알고리즘들이 고정된 특정 모델공간 좌표계를 기준으로 서로의 위치 및 자세를 추정하는 것이 아니라, 오직 두 영상간의 상대적인 위치 및 자세만을 추정할 수 있기 때문에, 고정된 카메라로 촬영된 영상 시퀀스 각각의 프레임마다 수립된 모델공간의 좌표계 기준들이 서로 일치되기 어렵다는 점에 기인한다고 할 수 있다. 그런 반면, 제안 알고리즘의 경우에는 사전 기하학적 제약조건을 도입함으로써 결과적으로 모델공간의 좌표계 기준들이 서로 유사하게 수립될 수 있도록 제한할 수 있었 기 때문에, 이를 고려하지 못한 다른 비교 알고리즘과는 달 리 기하구조 추정의 일관성 확보가 가능했던 것으로 분석 된다. 이러한 결과는 에피폴라 변환결과에서 명확하게 드 러났다. 그림 5 는 TEST 02 의 에피폴라 변환결과 중에 그 일부를 나타낸 것으로, 제안 알고리즘은 기존 알고리즘과 는 달리 연속적으로 유사한 형태의 변환결과를 산출할 수 있었다. 또한 추가적인 분석으로, 영상 변형도와 왜곡도 측 면에서도 제안 알고리즘은 가장 우수한 것으로 확인되었다. 이러한 결과들은 제안 알고리즘이 $3 \mathrm{D}$ 영화와 같은 이미지 시퀀스 형태의 $3 \mathrm{D}$ 콘텐츠 처리에 매우 적합함을 보여주는 결과라 할 수 있다.

한편 Case 1의 경우는 두 영상자료 모두에서 다른 비교 알고리즘들에 비해 확연히 저감된 정확도를 나타내었는데, 이는 직접선형변환모델의 단점인 정합점 위치오차에 대한 민감성 문제에 기인한 결과로 분석된다.

표 3의 성능검증 실험에서는 임의의 한 장면에 대한 영상 시퀀스의 편위수정을 위해 각 프레임 마다 기하구조가 추 정되었고, 이로부터 영상의 수직시차 제거를 위한 에피폴
라 변환이 수행되었다. 그러나 현실적으로 실제 $3 \mathrm{D}$ 콘텐츠 제작에 있어서 상기의 방식은 합리적이지 못한 방식이라 할 수 있다. 그 이유는 바로 영상 시퀀스 처리에 있어 기하 구조 추정의 비일관성 문제 때문이다. 따라서 고정된 임의 의 한 장면에 대해서는 그 장면을 대표할 수 있는 단일의 기하구조로부터 일괄적으로 에피폴라 변환을 수행하는 것 이 바람직할 것이며, 그 대표 기하구조를 결정하는 가장 쉬 운 방법으로는 각 영상별 산출된 기하구조의 평균을 이용 하는 방법일 것이다. 다음의 표 4는 TEST 01과 02에 대해 각 방식별로 산출된 평균 기하구조를 적용한 결과이다. 여 기서는 앞서 표 3에서와는 달리 사전에 패턴영상들로부터 기하구조가 추정되는 스테레오 캘리브레이션 방식(Case 3) 이 비교 알고리즘으로 사용되었다.

표 4. 방식별 평균 기하구조를 적용한 성능분석결과

Table 4. Evaluation results applied average geometry

\begin{tabular}{c|c|c|c}
\hline \hline \multicolumn{2}{c|}{} & $e_{\text {line }}$ (pixel) & $e_{\text {rect }}$ (pixel) \\
\hline \multirow{4}{*}{ TEST_01 } & Case 1 & 1.7468 & 3.1678 \\
\cline { 2 - 4 } & Case 2 & 0.5269 & 0.4843 \\
\cline { 2 - 4 } & Case 3 & 0.7658 & 0.5897 \\
\cline { 2 - 4 } & Case 4 & 0.3224 & 0.3339 \\
\cline { 2 - 4 } & Case 5 & 0.5438 & 0.4394 \\
\hline \multirow{4}{*}{ TEST_02 } & Case 1 & 1.7970 & 1.3824 \\
\cline { 2 - 4 } & Case 2 & 0.6389 & 0.5762 \\
\cline { 2 - 4 } & Case 3 & 0.7919 & 0.6436 \\
\cline { 2 - 4 } & Case 4 & 0.6607 & 0.5937 \\
\cline { 2 - 4 } & Case 5 & 0.3801 & 0.3339 \\
\hline \hline
\end{tabular}

실험결과, 대표기하구조를 적용한 결과는 개별 처리된 방식의 결과(표 3)보다 전반적으로 향상된 정확도를 보여 주었으며, 특히 제안 알고리즘인 Case 5 의 경우는 가장 큰 정확도 향상을 나타내었다.

표 3. TEST 01과 02에 대한 알고리즘별 성능측정 결과

Table 3. Evaluation results of each algorithms using TEST 01 and TEST 02

\begin{tabular}{c|c|c|c|c|c|c}
\hline \hline \multirow{2}{*}{ Method } & \multicolumn{3}{|c|}{ TEST 01 } & \multicolumn{3}{c}{ TEST 02 } \\
\cline { 2 - 7 } & $e_{\text {line }}$ (pixel) & $e_{\text {rect }}$ (pixel) & $v_{\text {slope }}$ (deg.) & $e_{\text {line }}$ (pixel) & $e_{\text {rect }}$ (pixel) & $v_{\text {slope }}$ (deg.) \\
\hline Case 1 & $1.49 \pm 0.99$ & $5.43 \pm 19.55$ & 19.58 & $1.92 \pm 1.41$ & $10.99 \pm 68.62$ & 18.88 \\
\hline Case 2 & $0.54 \pm 0.17$ & $0.49 \pm 0.13$ & 4.26 & $0.74 \pm 0.65$ & $0.80 \pm 1.84$ & 5.55 \\
\hline Case 4 & $0.39 \pm 0.15$ & $0.39 \pm 0.16$ & 3.24 & $0.62 \pm 0.46$ & $0.61 \pm 0.59$ & 5.25 \\
\hline Case 5 & $0.57 \pm 0.07$ & $0.46 \pm 0.05$ & 0.29 & $0.57 \pm 0.53$ & $0.49 \pm 0.45$ & 0.55 \\
\hline \hline
\end{tabular}



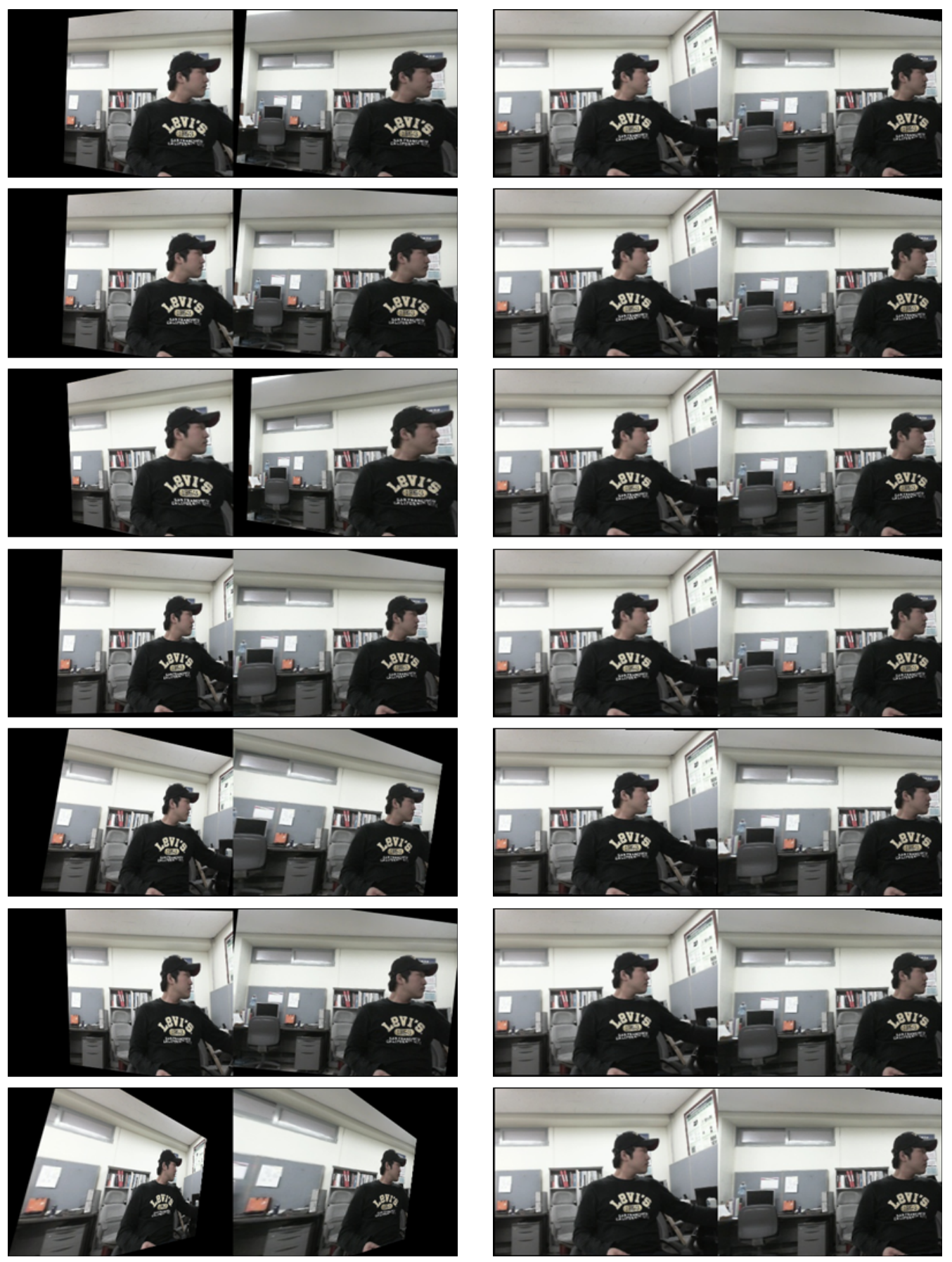

(a) Case 2

(b) Case 5 (proposed algorithm)

그림 5. 연속된 프레임에 대한 영상 편위수정 결과 (Case 2와 Case 5)

Fig. 5. Rectification result (Case 2 and Case 5) of consecutive image frames 


\section{IV. 결론}

본 논문에서는 3D 콘텐츠 제작을 위한 스테레오 영상의 수직시차 제거에 있어 베이지안 접근방식을 적용한 사진측 량기반의 강인 편위수정 기법이 제안되었다. 영상의 편위 수정 과정을 크게 기하추정 단계와 에피폴라 영상 변환단 계로 나누었을 때, 본 논문에서는 기하구조 추정을 위해 베 이지안 접근방식을 적용한 상대표정 알고리즘을 이용하여 오차요인에 대한 강인성과 기하구조 추정상의 일관성을 확 보하고자 하였으며, 에피폴라 변환에는 공선조건에 기반한 비선형적 중심투영변환 알고리즘을 적용함으로써, 기하학 적 왜곡과 원 영상 대비 변형을 최소화하고자 하였다. 알고 리즘 검증실험에는 기존 컴퓨터비전 알고리즘을 비교알고 리즘으로 채택하여 성능비교를 수행하였으며, 제작된 두 세트의 실험영상자료로부터 개별 프레임에 대한 성능분석 과 이로부터 산출된 평균 기하구조로부터 각 실험자료 전 체에 대한 성능분석이 이루어졌다. 실험결과, 두 실험 모두 에서 제안 알고리즘은 오차 요인에 대해 가장 강인함을 보 여주었으며 또한 다른 비교 알고리즘에 비해 원 영상 대비 기하학적 변형이 가장 적게 발생됨을 보여주었다.

본 연구에서 개발된 사진측량기반의 편위수정 알고리즘 은 실제 $3 \mathrm{D}$ 콘텐츠 제작 시 다변적 촬영환경으로 인해 발생 될 수 있는 오차요인들에 대해서 강인함과 높은 정확도 보 장이 가능할 뿐 아니라, 또한 영상의 변형을 최소화 할 수 있다는 점에서 $3 \mathrm{D}$ 영화와 같은 영상 시퀀스 형태의 $3 \mathrm{D}$ 콘 텐츠 처리에 그 활용적 가치가 매우 높다고 판단된다. 이에 따라, $3 \mathrm{D}$ 콘텐츠가 가질 수 있는 신뢰성을 보다 향상시킬 수 있을 것으로 기대되며, 나아가 산업시장에서의 경쟁력 확보에도 큰 기여를 하게 될 것으로 기대된다.

\section{참 고 문 헌}

[1] H. Kim, H. Kim, H. Jang, S. Nam, 2011. Technical trend of stereoscopic content production, Electronics and Telecommunications Trends, 26(1):13-24.

[2] Y.-S. Kang and Y.-S. Ho, 2011. An efficient image rectification method for parallel multi-camera arrangement, IEEE Trans. Consumer Electronics, 57(3):1041-1048.

[3] Z. Zhang, 2000. A flexible new technique for camera calibration, IEEE Transaction on Pattern Analysis and Machine Intelligence, 22(11):1330-1334.

[4] D. C. Brown, 1971. Close-range camera calibration, Photogrammetric Engineering, 37(8):855-866.

[5] R. I. Hartley, 1999. Theory and practice of projective rectification, International Journal of Computer Vision, 35(2):115-127.

[6] C. Loop, Z. Zhang, 1999. Computing rectifying homographies for stereo vision, Proceedings of the IEEE Conference on Computer Vision and Pattern Recognition, vol. 1, pp. 125 - 131.

[7] K. A. A1-Shalfan, J. G. B. Haigh, S. S. Ipson, 2000. Direct algorithm for rectifying pairs of uncalibrated images, Electronics Letters, 36(5):419-420.

[8] R. I. Hartley, A. Zisserman, 2003. Multiple View Geometry in Computer Vision, 2nd Edition, New York: Cambridge University Press.

[9] J. Mallon and P. F. Whelan, 2005. Projective rectification from the fundamental matrix, 23(7):643-650.

[10] J. Kim, T. Kim, 2012. Precise rectification of misaligned stereo images for 3D image generation, Journal of Broadcast Engineering, $17(2): 411-421$.

[11] J. Grodecki and G. Dial, 2003. Block adjustment of high-resolution satellite images described by rational polynomials, Photogrammetric Engineering \& Remote Sensing, 69(1):59-68.

[12] B. Yeu, T. Schenk, 2003. Modern Digital Photogrammetry, Seoul: Pearson Education Korea.

[13] R. I. Hartley, 1995. In defence of the eight-point algorithm, Proc. of IEEE International Conference on Computer Vision, pp.1064-1070.

[14] OpenCV library, http://sourceforge.net/projects/opencvlibrary.

[15] D. G. Lowe, 2004. Distinctive image features from scale-invariant keypoints, International Journal of Computer Vistion, 60(2):91-110.

[16] M. A. Fischler and R. C. Bolles, 1981. Random Sample Consensus: A Paradigm for Model Fitting with Applications to Image Analysis and Automated Cartography, Comm. of the ACM 24(6):381 - 395. 


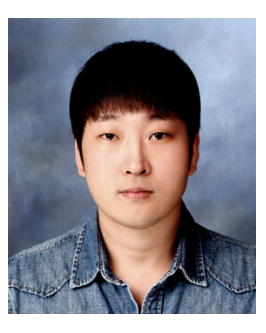

\section{김 재 인}

- 2010년 8월 : 인하대학교 지리정보공학과 학사

- 2010년 9월 현재 : 인하대학교 지리정보공학과 석사과정

- 주관심분야 : 3D 입체영상 생성, 위성영상 품질평가, 위성영상 활용

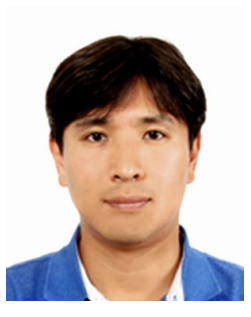

김 태 정

- 1991년 8월 : 한국과학기술원 전자공학과 학사

- 1992년 10월 : University College London 석사(위성공학)

- 1996년 2월 : University College London 박사(원격탐사)

- 1995년 8월 2001년 3월 : KAIST 인공위성연구센터 선임연구원

- 2001년 4월 2003년 8월 : KAIST 인공위성연구센터 연구교수

- 2003년 9월 현재: 인하대학교 지리정보공학과 정교수

- 주관심분야 : 스테레오매칭, 3D 입체영상 생성, 센서모델링, 자동 DEM 생성, 수치도화기 개발 